\title{
Assessment of genetic diversity and variation of Robinia pseudoacacia seeds induced by short-term spaceflight based on two molecular marker systems and morphological traits
}

C.Q. Yuan ${ }^{1}$, Y.F. Li ${ }^{1}$, P. Sun ${ }^{1}$, Y.H. Sun ${ }^{1}$, G.J. Zhang ${ }^{2}$, M.S. Yang ${ }^{3}$, Y.Y. Zhang ${ }^{3}$, Y. Li ${ }^{1}$ and L. Wang ${ }^{4}$

${ }^{1}$ National Engineering Laboratory for Tree Breeding, Key Laboratory of Genetics and Breeding in Forest Trees and Ornamental Plants, Ministry of Education, College of Biological Sciences and Biotechnology, Beijing Forestry University, Beijing, P.R. China ${ }^{2}$ College of Horticulture Science and Technology, Hebei Normal University of Science and Technology, Qinhuangdao, P.R. China ${ }^{3}$ Institute of Forest Biotechnology, Forestry College, Agricultural University of Hebei, Baoding, P.R. China ${ }^{4}$ College of Forestry, Beijing Forestry University, Beijing, P.R. China

Corresponding author: Y. Li

E-mail: yunli@bjfu.edu.cn

Genet. Mol. Res. 11 (4): 4268-4277 (2012)

Received March 5, 2012

Accepted November 29, 2012

Published December 17, 2012

DOI http://dx.doi.org/10.4238/2012.December.17.2

\begin{abstract}
The black locust (Robinia pseudoacacia) is a forest legume that is highly valued as a honey plant and for its wood. We explored the effect of short-term spaceflight on development of $R$. pseudoacacia seedlings derived from seeds that endured a 15-day flight; the genetic diversity and variation of plants sampled from spacemutagenized seeds were compared to plants from parallel groundbased control seeds using molecular markers and morphological traits. In the morphology analysis, the space-mutagenized group had
\end{abstract}


apparent variation compared with the control group in morphological traits, including plant height, basal diameter, number of branches, branch stipular thorn length, branch stipular thorn middle width, leaflet vertex angle, and tippy leaf vertex angle. Simple sequence repeat (SSR) and sequence-related amplified polymorphism (SRAP) molecular marker analyses showed a slightly higher levels of genetic diversity in the space-mutagenized group compared to the control group. In the SRAP analysis, the space-mutagenized group had 115 polymorphic bands $v s 98$ in the controls; $91.27 \%$ polymorphic loci $v s$ $77.78 \%$ in the controls; $1.9127 \pm 0.2834$ alleles $v s \quad 1.7778 \pm 0.4174$ in the controls; Nei's genetic diversity $(h)$ was $0.2930 \pm 0.1631$ vs 0.2688 \pm 0.1862 in the controls, and the Shannon's information index $(I)$ was $0.4452 \pm 0.2177$ vs $0.4031 \pm 0.2596$ in the controls. The number of alleles was significantly higher in the space-mutagenized group. In the SSR analysis, the space-mutagenized group also had more polymorphic bands (51 vs 46), a greater percentage of polymorphic loci $(89.47 \%$ vs $80.70 \%)$; $h$ was also higher $(0.2534 \pm 0.1533$ vs $0.2240 \pm 0.1743)$, as was $I(0.3980 \pm 0.2069$ vs $0.3501 \pm 0.2412)$. These results demonstrated that the range of genetic variation in the populations of $R$. pseudoacacia increased after spaceflight. It also suggested that the SSR and SRAP markers are effective markers for studying mutations and genetic diversity in R. pseudoacacia. The data provide valuable molecular evidence for the effects of the space environment on $R$. pseudoacacia and may contribute to future spacebreeding programs involving forest trees.

Key words: Genetic diversity; Molecular markers; Spaceflight; Morphological traits; Robinia pseudoacacia

\section{INTRODUCTION}

The unique environment of outer space, including weightlessness, high charge, high radiation, high-energy particles, and features not present on Earth, can directly or indirectly affect metabolic activities and cause heritable DNA mutations in plants (Mashinsky and Nechitailo, 2001). However, the molecular effects of space environments on plants are largely unknown. Molecular-marker techniques have been widely used for detecting genetic mutations after space flight, including inter-simple sequence repeat markers (Gao et al., 2009; Wu et al. 2011), simple sequence repeat (SSR) markers (Zhou et al., 2007; Xiao et al., 2009; He et al., 2010; Lu et al., 2010), amplified fragment length polymorphism markers (Yi et al., 2002; Li et al., 2007; Lu et al., 2010; Sun et al., 2010), random amplification of polymorphic DNA (RAPD) markers (Liu et al., 1999; Gao et al., 2000; Yi et al., 2002; Nechitailo et al., 2005; Xie et al., 2010), and sequence-related amplified polymorphism (SRAP) markers (Chen et al., 2009; Wang et al., 2009). Among these molecular markers, SSRs are often employed because of their reproducibility, codominant inheritance, relative abundance, multiallelic nature, good genome coverage, and high frequency of polymorphism detection (Powell et al., 1996; 
McCouch et al., 2002; Lu et al., 2010). However, the generated polymorphisms are limited to defined chromosomal segments. In contrast, SRAP markers combine reliability, simplicity, moderate throughput, and easy sequencing of selected bands. Furthermore, SRAP targets coding sequences in the genome and results in a moderate number of codominant markers ( $\mathrm{Li}$ and Quiros, 2001). Thus, SRAP and SSR markers are complementary techniques for polymorphism analyses.

Although significant achievements have been made in spaceflight-induced mutation breeding, most studies have focused on crops; research on spaceflight-induced mutations in forest trees is in its infancy. Furthermore, the effects of space environments on plants, especially forest trees, at the molecular level are largely unknown. This limits the application of spaceflight-induced mutation on forest-tree breeding.

Robinia pseudoacacia displayed superior growth rates, energy yields, and other attractive traits (Stringer and Carpenter, 1986). In addition, $R$. pseudoacacia has advantages such as alkali resistance, drought and cold tolerance, and extensive adaptability; therefore, it has become an important ecological plant in China. However, for the traditional breeding of $R$. pseudoacacia, its breeding cycle is too long and produces limited variations. $R$. pseudoacacia can be propagated by asexual reproduction; therefore, once a beneficial mutation is obtained from spaceflight, it can be quickly produced and utilized.

Here, we present the first comparative analysis of genetic diversity among spaceinduced mutagenesis and ground-based control populations of R. pseudoacacia using SSR and SRAP molecular markers and morphological traits. Our objectives were to determine differences in genetic diversity between ground-based control and space-mutagenized seedlings of seeds that endured a 15-day flight, both at the molecular and morphological levels.

\section{MATERIAL AND METHODS}

\section{Plant materials}

Healthy, mature seeds of R. pseudoacacia from open-pollinated plants were collected from Henan Province of China in 2005. The seeds were randomly divided into 2 groups. One group was flown on the 'Shijian No. 8' breeding satellite for a 15-day spaceflight (September 9-24, 2006). The satellite had a 355-h flying time within $187 \mathrm{~km}$ for perigee and $463 \mathrm{~km}$ for apogee. The other group was kept on the ground and was later used as the ground-based control. Both the spaceflight and the ground-based control seeds were planted at the Experimental Station of Yanqing Sandstorm Source Centre in Beijing in 2007 under the same conditions. The field trial was conduced using a complete randomized block design with 3 replicates.

A total of 120 individual plants were randomly selected, including 60 space-mutagenized plants (SM) and 60 ground-based controls (OS). Young leaves were collected from each of the selected trees in May 2010 and were transported in a foam box containing ice bags and stored at $-80^{\circ} \mathrm{C}$ for genomic DNA extraction.

\section{Isolation of genomic DNA}

Total genomic DNA from each leaf sample was extracted from $100 \mathrm{mg}$ young leaves using the DNAsecure Plant Kit (TIANGEN, Beijing) according to manufacturer instructions. 
The genomic DNA was quantified on $1.0 \%$ agarose gels, and the DNA concentration was determined using a NanoVue ultramicrospectrophotometer. The samples were then diluted to a final concentration of about $20 \mathrm{ng} / \mu \mathrm{L}$ and stored at $-20^{\circ} \mathrm{C}$ before polymerase chain reaction (PCR) amplification.

\section{SSR amplification and selection of optimum primers}

A total of 21 SSR primers [Generay Biotech (Shanghai) Co., Ltd., China] described by Lian and Hogetsu (2002), Lian et al. (2004), and Mishima et al. (2009) were initially screened in 10 samples from the SM and the OS individuals. Primers were excluded from the study if they did not show different band sizes or consistently failed to amplify products in 10 samples. A final set of 12 SSR primers that produced clear and reproducible fragments were selected for further analysis (Table 1).

\begin{tabular}{|c|c|c|c|c|c|}
\hline Locus & Motif & Primer sequence & Total number of alleles & Size ranges (bp) & PIC \\
\hline Rops08 & $(\mathrm{CA})_{8} \mathrm{TA}(\mathrm{CA})_{3}$ & $\begin{array}{l}\text { TTCTGAGGAAGGGTTCCGTGG } \\
\text { GTTAAAGCAACAGGCACATGG }\end{array}$ & 7 & $191-205$ & 0.5631 \\
\hline Rp102 & $(\mathrm{GA})_{12}$ & $\begin{array}{l}\text { CCAAATCTCAAAATGTGCTAAGTAGC } \\
\text { ACTTGGGCTATGGTATTGCA }\end{array}$ & 3 & 205-211 & 0.5296 \\
\hline Rp206 & $(\mathrm{GT})_{9}$ & $\begin{array}{l}\text { GCCAAATCCCATTAGATCACAGTTGA } \\
\text { AGAAGTTAGACTTACGTGCTGC }\end{array}$ & 7 & $222-246$ & 0.5637 \\
\hline Rops16 & $(\mathrm{CT})_{13}$ & $\begin{array}{l}\text { AACCCTAAAAGCCTCGTTATC } \\
\text { TGGCATTTTTTGGAAGACACC }\end{array}$ & 5 & $195-223$ & 0.6663 \\
\hline Rops05 & $(\mathrm{AC})_{2} \mathrm{GC}(\mathrm{AC})_{7}$ & $\begin{array}{l}\text { TGGTGATTAAGTCGCAAG } \\
\text { GTGGTTGTGACTTGTACGTAAGTC }\end{array}$ & 3 & $120-138$ & 0.5780 \\
\hline Rops15 & $(\mathrm{CT})_{20}$ & $\begin{array}{l}\text { GCCCATTTTCAAGAATCCATATATTGG } \\
\text { TCATCCTTGTTTTGGACAATC }\end{array}$ & 8 & $112-254$ & 0.8202 \\
\hline Rops150 & $(\mathrm{TC})_{3} \mathrm{TT}(\mathrm{TC})_{12}$ & $\begin{array}{l}\text { TCGTTGGATCAACATGCATGG } \\
\text { ACAGAACCCTAACCCTAGCA }\end{array}$ & 7 & $199-217$ & 0.7180 \\
\hline Rops06 & $(\mathrm{GT})_{3} \mathrm{ACA}(\mathrm{GT})_{11}$ & $\begin{array}{l}\text { CTAAGGAGGTGCTGACCCTC } \\
\text { TTAATCTGTGATGGGACACTG }\end{array}$ & 3 & $117-144$ & 0.5542 \\
\hline Rops02 & $(\mathrm{AC})_{13}(\mathrm{AT})_{4}$ & $\begin{array}{l}\text { CAGAACTGTGGAGAATAATTCTGAACCG } \\
\text { CGCCATCTGTTAGTTTGTTGC }\end{array}$ & 2 & $107-138$ & 0.4998 \\
\hline Rops18 & $(\mathrm{AC})_{8}$ & $\begin{array}{l}\text { AGATAAGATCAAGTGCAAGAGTGTAAG } \\
\text { TAATCCTCGAGGGAACAATAC }\end{array}$ & 3 & $135-219$ & 0.4763 \\
\hline Rp109 & $(\mathrm{AG})_{17}$ & $\begin{array}{l}\text { GAGGAATCACAAAACCGTTTGG } \\
\text { TGGGATTTGAGAGAGTGGTGGTG }\end{array}$ & 5 & $136-160$ & 0.7066 \\
\hline Rp200 & $(\mathrm{AG})_{23}$ & $\begin{array}{l}\text { GGTTTCTTTGTTCACCTGCTCTGG } \\
\text { ACCTACGTGTCCACGGCTCT }\end{array}$ & 4 & $160-198$ & 0.8493 \\
\hline $\begin{array}{l}\text { Total } \\
\text { Mean }\end{array}$ & & & $\begin{array}{c}57 \\
4.5\end{array}$ & & 0.6271 \\
\hline
\end{tabular}

SSR amplification was carried out by an ABI 9700 thermal cycler in a $12.5-\mu \mathrm{L}$ reaction mixture containing 20 ng genomic DNA, 1 X Taq buffer, $2.5 \mathrm{mM} \mathrm{MgCl}_{2}, 0.25 \mathrm{mM}$ dNTPs, $0.15 \mu \mathrm{M}$ of each primer pair, and $0.25 \mathrm{U}$ Taq DNA polymerase. The amplification reaction was performed with an initial denaturation step at $94^{\circ} \mathrm{C}$ for $5 \mathrm{~min}, 10$ cycles of $94^{\circ} \mathrm{C}$ for $30 \mathrm{~s}, 63^{\circ}$ to $53^{\circ} \mathrm{C}$ for 30 $\mathrm{s}$ (decreasing at $1^{\circ} \mathrm{C}$ per cycle), and $72^{\circ} \mathrm{C}$ for $90 \mathrm{~s}$, then 20 cycles at the annealing temperature $\left(53^{\circ} \mathrm{C}\right.$ ), and finally an extension at $72^{\circ} \mathrm{C}$ for $10 \mathrm{~min}$. The amplified products were electrophoresed on $8.0 \%$ non-denaturing polyacrylamide gels run at $200 \mathrm{~V}$ in $1 \mathrm{X}$ TBE buffer, visualized by silver staining $(1 \mathrm{~g} / \mathrm{L})$, and photographed with GS-800 Calibrated Densitometer (Bio-Rad). The molecular sizes of the amplified fragments were estimated by comparison to a DL2000 DNA marker. 


\section{SRAP amplification and selection of optimum primers}

Using the optimized SRAP-PCR system previously reported (Yuan et al., 2011), 12 primer combinations that generated strong and clear amplified bands were selected for further population investigations (Table 2). The SRAP-PCR conditions were reported previously (Yuan et al., 2011). The reaction volume of $12.5 \mu \mathrm{L}$ consisted of $0.30 \mu \mathrm{M}$ of each primer pair, $2.5 \mathrm{mM} \mathrm{MgCl}_{2}, 0.2 \mathrm{mM}$ dNTPs, $0.75 \mathrm{U}$ Taq DNA polymerase, and $30 \mathrm{ng}$ genomic DNA. DNA amplifications were performed with an initial step at $94^{\circ} \mathrm{C}$ for $5 \mathrm{~min}, 5$ cycles of $1 \mathrm{~min}$ at $94^{\circ} \mathrm{C}$, $1 \mathrm{~min}$ at $35^{\circ} \mathrm{C}$, and $1.5 \mathrm{~min}$ at $72{ }^{\circ} \mathrm{C}$, then 35 cycles of $94^{\circ} \mathrm{C}$ for $1 \mathrm{~min}, 50^{\circ} \mathrm{C}$ for $1 \mathrm{~min}$, and $72^{\circ} \mathrm{C}$ for $1.5 \mathrm{~min}$, and a final extension at $72^{\circ} \mathrm{C}$ for $10 \mathrm{~min}$ ( $\mathrm{Li}$ and Quiros, 2001). The PCRs were carried out in an ABI 9700 thermal cycler. The SRAP-PCR products were analyzed on $8.0 \%$ non-denaturing polyacrylamide gels in $1 \mathrm{X}$ TBE buffer run at a constant voltage of $200 \mathrm{~V}$ for 70 min, silver stained, and then photographed with a GS-800 Calibrated Densitometer (Bio-Rad).

\begin{tabular}{|c|c|c|c|}
\hline Primer combinations & No. of bands & No. of polymorphic bands & Polymorphism (\%) \\
\hline Em6-Me6 & 8 & 7 & 87.50 \\
\hline Em9-Me11 & 9 & 7 & 77.78 \\
\hline Em6-Me4 & 12 & 11 & 91.67 \\
\hline Em5-Me12 & 9 & 9 & 100.00 \\
\hline Em5-Me9 & 11 & 10 & 90.91 \\
\hline Em4-Me12 & 10 & 9 & 90.00 \\
\hline Em12-Me11 & 8 & 7 & 87.50 \\
\hline Em11-Me11 & 13 & 12 & 92.31 \\
\hline Em5-Me6 & 11 & 10 & 81.82 \\
\hline Em5-Me5 & 9 & 9 & 100.00 \\
\hline Em4-Me13 & 9 & 9 & 100.00 \\
\hline Em4-Me11 & 17 & 16 & 94.12 \\
\hline Total & 126 & 116 & \\
\hline Mean & 10.5 & 9.7 & 91.13 \\
\hline
\end{tabular}

\section{Morphological data}

Twenty-two morphological traits were measured from each single tree of the 3 replicates of the field trial during 2 growing seasons of 2009-2011. These traits included plant height (PH), basal diameter (BD), number of branches (NB), knot spacing, trunk prickle length (TPL), trunk prickle base width, trunk prickle middle width (TPMW), branch stipular thorn length (BSTL), branch stipular thorn base width (BSTBW), branch stipular thorn middle width (BSTMW), number of leaflets of pinnate fronds, pinnate frond petiole length, leaflet length, leaflet width, leaflet petiole length (LPL), leaflet vertex angle (LVA), leaflet base angle, tippy leaf length, tippy leaf width, tippy leaf petiole length (TLPL), tippy leaf vertex angle (TLVA), and tippy leaf base angle. The means, maximum and minimum values, standard deviation, and coefficients of variation (CV) were calculated for each of the 22 morphological characteristics. These traits were chosen and measured according to the literature (The People's Republic of China Ministry of Agriculture, 2002).

\section{Data analysis}

The amplified fragments that were clear and well defined for SRAP were scored as either absent (0) or present (1) for all specimens. The genetic parameters of observed number of 
alleles $\left(N_{\mathrm{O}}\right)$, effective number of alleles $\left(N_{\mathrm{E}}\right)$, number of polymorphic bands $(P)$, percentage of polymorphic loci $(P P L)$, Shannon's information index $(I)$, and Nei's gene diversity index $(h)$ were calculated using the POPGENE32 software. For SSR analysis, the bands were scored for each of the microsatellite primer pairs in each specimen based on presence or absence of the allele at a given locus, generating a matrix of 1 and 0 . The PIC value of SSR loci was measured using the formula developed by Nei, (1973): $P I C=1-\sum X_{k}^{2}$, where $X_{k}$ is the frequency of the $k^{\text {th }}$ allele in the set of species investigated. SPSS (version 16, Chicago, IL, USA) was used for statistical analysis.

After the homogeneity of sample variances was verified using the Levene test, an independent sample $t$-test was used to compare means between the SM and OS groups for all morphological characteristics using the SPSS 16.0 software.

\section{RESULTS}

\section{SSR analysis}

Of 21 SSR primers, only 12 (57\%) showed polymorphisms among SM and OS groups. The remaining 9 markers were either unstable or monomorphic in the present study. The polymorphic SSR markers showed 2 (in Rops02) to 8 (in Rops15) alleles with an average of 4.5 alleles per locus (Table 1). The PIC value varied from 0.4763 to 0.8493 with an average of 0.6271 per marker. Low PIC values were observed for the primers of Rops18 (0.4763) and Rops02 (0.4998). The PIC values of the remaining microsatellite loci were above 0.50 (Table 1).

At the group level, the SM group showed more polymorphic bands (51) and a slightly higher percentage of polymorphic loci (89.47\%) than the OS group (46, 80.70\%) (Table 3$)$. In addition to $P$ and $P P L, h$ (Nei, 1973) and $I$ were also calculated to estimate the level of genetic diversity. At the group level, the SM group showed higher $h$ and $I$ values $(0.2534 \pm 0.1533$ and $0.3980 \pm 0.2069)$ compared to the OS group $(0.2240 \pm 0.1743$ and $0.3501 \pm 0.2412)$ (Table 3$)$.

Table 3. Genetic variations of Robinia pseudoacacia based on SSR marker.

\begin{tabular}{lccccc}
\hline Group & Sample size & $h$ & $I$ & $P L$ & $P P L(\%)$ \\
\hline SM & 60 & $0.2534 \pm 0.1533$ & $0.3980 \pm 0.2069$ & 51 & 89.47 \\
OS & 60 & $0.2240 \pm 0.1743$ & $0.3501 \pm 0.2412$ & 46 & 80.70 \\
\hline
\end{tabular}

Data are reported as means $\pm \mathrm{SD} . h=$ Nei's gene diversity; $I=$ Shannon's information index; $P L=$ number of polymorphic loci; $P P L=$ percentage of polymorphic loci. $\mathrm{SM}=$ space-mutagenized plants; $\mathrm{OS}=$ ground-based controls.

\section{SRAP analysis}

A total of 126 amplified bands were generated with 12 selected primers across the 120 plants in the SM and OS groups with an average of 10.5 bands per primer pair. Among these bands, 116 were polymorphic $(\mathrm{P}=92.06 \%)$. The number of polymorphic bands generated by each primer ranged from 7 (em6/me6, em $9 / \mathrm{me} 11$, and em12/me11) to $16(\mathrm{em} 4 / \mathrm{me} 11)$ with an average of 9.7 per primer (Table 2).

At the group level, $P$ and $P P L$ in the SM group were 115 and $91.27 \%$, respectively, which was higher than that of the OS group (98 and $77.78 \%$, respectively). $N_{\mathrm{O}}$ for the SM group was $1.9127 \pm 0.2834$, which differed significantly from that of the OS group (1.7778 \pm 0.4174 ) (Table 4). Moreover, $N_{\mathrm{E}}, h(\mathrm{Nei}, 1973)$, and $I$ were also used to estimate the level of 
genetic diversity. At the group level, the SM group showed higher $N_{\mathrm{E}}, h$, and $I$ values (1.4887 $\pm 0.3302,0.2930 \pm 0.1631$, and $0.4452 \pm 0.2177$, respectively) than the OS group (1.4570 \pm $0.3597,0.2688 \pm 0.1862$, and $0.4031 \pm 0.2596$, respectively) (Table 4).

Table 4. Genetic variations of Robinia pseudoacacia based on SRAP marker.

\begin{tabular}{|c|c|c|c|c|c|c|c|}
\hline Group & Sample size & $N_{\mathrm{O}}$ & $N_{\mathrm{E}}$ & $h$ & $I$ & $P$ & $P P L(\%)$ \\
\hline SM & 60 & $1.9127 \pm 0.2834^{*}$ & $1.4887 \pm 0.3302$ & $0.2930 \pm 0.1631$ & $0.4452 \pm 0.2177$ & 115 & 91.27 \\
\hline OS & 60 & $1.7778 \pm 0.4174$ & $1.4570 \pm 0.3597$ & $0.2688 \pm 0.1862$ & $0.4031 \pm 0.2596$ & 98 & 77.78 \\
\hline
\end{tabular}

$N_{\mathrm{O}}=$ observed number of alleles; $N_{\mathrm{E}}=$ effective number of alleles; $h=$ Nei's gene diversity; $I=$ Shannon's information index; $P=$ number of polymorphic loci; $P P L=$ percentage of polymorphic loci; $\mathrm{SM}=$ space-mutagenized plants; $\mathrm{OS}$ = ground-based controls. *Indicate significant difference compared to $\mathrm{OS}$ at the 0.05 probability level.

\section{Morphology analysis}

The CV values for 10 of the characteristics exhibited a high level of variation ( $>30 \%)$ across both groups. These included NB, TPL, TPMW, BSTL, BSTBW, BSTMW, LPL, LVA, TLPL, and TLVA (Table 5). Comparing the 22 characteristics, the number of branches showed the highest degree of variation ( $\mathrm{CV}=50.82 \%$ in the SM group and $49.67 \%$ in the OS group), and the number of leaflets of pinnate fronds showed the least variation (CV $=15.61 \%$ in the SM group and $15.24 \%$ in the OS group; Table 5). As a whole, the SM group showed slightly higher CV values in comparison with the OS group. The analysis of variance (mean square) shown in Table 5 revealed that some characteristics were significantly different between the SM and OS groups. These included $\mathrm{PH}(\mathrm{P}=0.038), \mathrm{BD}(\mathrm{P}$ $=0.000), \mathrm{NB}(\mathrm{P}=0.004), \mathrm{BSTL}(\mathrm{P}=0.001)$, BSTMW $(\mathrm{P}=0.014), \mathrm{LVA}(\mathrm{P}=0.000)$, and TLVA $(\mathrm{P}$ $=0.037)$. Other characteristics did not show significant differences between the 2 groups $(\mathrm{P}>0.05)$.

Table 5. Morphological classification of characters and basic statistical data of samples.

\begin{tabular}{|c|c|c|c|c|c|c|c|c|c|c|c|}
\hline \multirow[t]{2}{*}{ Code } & \multirow[t]{2}{*}{ Morphological traits } & \multicolumn{5}{|c|}{ SM group } & \multicolumn{5}{|c|}{ OS group } \\
\hline & & Mean & Max. & Min. & SD & $\mathrm{CV}(\%)$ & Mean & Max. & Min. & SD & $\mathrm{CV}(\%)$ \\
\hline $\mathrm{PH}$ & Plant height $(\mathrm{cm}) *$ & 354.50 & 568.00 & 161.00 & 81.70 & 23.05 & 379.70 & 587.00 & 192.00 & 92.11 & 24.26 \\
\hline $\mathrm{BD}$ & Basal diameter $(\mathrm{mm}) * *$ & 40.23 & 71.12 & 15.05 & 12.00 & 29.83 & 47.36 & 90.00 & 12.95 & 13.07 & 27.60 \\
\hline NB & Number of branches** & 8.54 & 25.00 & 1.00 & 4.34 & 50.82 & 10.45 & 27.00 & 2.00 & 5.19 & 49.67 \\
\hline KS & Knot spacing $(\mathrm{cm})$ & 3.06 & 4.70 & 1.50 & 0.64 & 20.92 & 3.06 & 5.55 & 0.83 & 0.76 & 24.84 \\
\hline TPL & Trunk prickles length (mm) & 11.21 & 30.59 & 3.18 & 4.99 & 44.51 & 12.70 & 22.95 & 3.96 & 4.04 & 31.81 \\
\hline TPBW & Trunk prickles base width (mm) & 6.87 & 13.23 & 2.48 & 1.77 & 25.76 & 7.16 & 10.59 & 2.55 & 1.84 & 5.70 \\
\hline TPMW & Trunk prickles middle width (mm) & 2.31 & 8.54 & 0.72 & 0.89 & 38.53 & 2.40 & 6.70 & 0.99 & 0.77 & 2.08 \\
\hline BSTL & Branch stipular thorn length $(\mathrm{mm})^{* *}$ & 10.46 & 22.97 & 1.98 & 4.69 & 44.84 & 12.08 & 24.19 & 2.73 & 4.64 & 38.41 \\
\hline BSTBW & Branch stipular thorn bas & 4.19 & 9.65 & 1.05 & 1.66 & 39.62 & 4.85 & 10.36 & 1.89 & 1.96 & 40.41 \\
\hline BSTMW & Branch stipular thorn middle width (mm)* & 1.88 & 5.54 & 0.44 & 0.72 & 38.30 & 2.08 & 4.33 & 0.67 & 0.80 & 38.46 \\
\hline NLPF & Number of leaflet of pinnate fronds & 17.74 & 25.00 & 11.00 & 2.77 & 15.61 & 17.65 & 24.00 & 13.00 & 2.69 & 15.24 \\
\hline PFPL & tiole length (mm) & 17.47 & 51.06 & 7.60 & 6.26 & 35.83 & 18.59 & 31.28 & 7.63 & 5.32 & 28.62 \\
\hline LL & Leaflet length (mm) & 27.73 & 61.67 & 6.65 & 10.60 & 38.23 & 31.15 & 49.49 & 10.22 & 8.46 & 27.16 \\
\hline LW & Leaflet width (mm) & 13.20 & 34.99 & 4.27 & 4.53 & 34.32 & 14.46 & 38.68 & 6.44 & 3.66 & 25.31 \\
\hline LPL & iole length ( & 2.22 & 5.98 & 0.81 & 0.77 & 34.68 & 2.59 & 5.54 & 0.64 & 0.87 & 33.59 \\
\hline LVA & Leaflet vertex angle $\left({ }^{\circ}\right)^{* *}$ & 136.07 & 303.09 & 54.98 & 43.70 & 32.12 & 113.47 & 245.56 & 49.96 & 39.67 & 34.96 \\
\hline LBA & Leaflet base angle $\left({ }^{\circ}\right)$ & 124.44 & 186.60 & 60.83 & 19.30 & 15.51 & 114.11 & 176.31 & 61.89 & 23.51 & 20.60 \\
\hline TLL & Tippy leaf length (mm) & 28.91 & 62.49 & 5.58 & 10.30 & 35.63 & 31.05 & 53.32 & 14.35 & 8.20 & 26.41 \\
\hline TLW & Tippy leaf width (mm) & 16.53 & 37.67 & 7.24 & 5.42 & 32.79 & 16.59 & 27.48 & 7.32 & 4.36 & 26.28 \\
\hline TLPL & Tippy leaf petiole length $(\mathrm{mm})$ & 9.17 & 22.55 & 3.14 & 3.61 & 39.37 & 9.28 & 15.92 & 2.60 & 2.83 & 30.50 \\
\hline TLVA & Tippy leaf vertex angle $\left({ }^{\circ}\right)^{*}$ & 176.46 & 300.96 & 59.53 & 67.20 & 38.08 & 144.27 & 288.25 & 58.69 & 57.97 & 40.18 \\
\hline TLBA & Tippy leaf base angle $\left(^{\circ}\right)$ & 99.47 & 141.57 & 68.22 & 15.70 & 15.78 & 93.59 & 137.75 & 52.86 & 18.15 & 19.39 \\
\hline
\end{tabular}

$\mathrm{SM}=$ space-mutagenized plants; $\mathrm{OS}=$ ground-based controls; Max. = maximum; Min. = minimum; $\mathrm{SD}=$ standard deviation; $\mathrm{CV}=$ coefficient of variation. *Significantly different compared to OS at the 0.05 probability level. **Significantly different compared to OS at the 0.01 probability level. 


\section{DISCUSSION}

In this study, genetic diversity between SM and OS R. pseudoacacia was analyzed by the SSR and SRAP marker systems combined with phenotypic traits.

The SSR and SRAP analyses showed that the SM group had a higher degree of genetic diversity $\left(P=115, P P L=91.27 \%, N_{\mathrm{O}}=1.9127 \pm 0.2834, N_{\mathrm{E}}=1.4887 \pm 0.3302, h=0.2930\right.$ $\pm 0.1631, I=0.4452 \pm 0.2177$ with SRAP marker system; $P=51, P P L=89.47 \%, h=0.2534$ $\pm 0.1533, I=0.3980 \pm 0.2069$ with the SSR marker system) than the OS group $(P=98, P P L$ $=77.78 \%, N_{\mathrm{O}}=1.7778 \pm 0.4174, N_{\mathrm{E}}=1.4570 \pm 0.3597, h=0.2688 \pm 0.1862, I=0.4031 \pm$ 0.2596 with the SRAP marker system; $P=46, P P L=80.70 \%, h=0.2240 \pm 0.1743, I=0.3501$ \pm 0.2412 with the SSR marker system). For morphological traits, there was also some variation between the SM and OS groups. This indicated that there are some variations in the SM population that may have been caused by spaceflight. It has been proposed that spaceflight exposure in seeds or plants could lead to mutants for crop improvement (Normile and Yimin, 2002; Liu et al., 2004), although the mechanisms of space-induced mutagenesis are largely unknown. In this study, the 2 groups of seeds (SM and OS) came from and were cultivated in the same source. The only difference between the 2 groups was that the SM group was exposed to the space environment for 15 days, while the OS group was kept on Earth. There are profound differences between spaceflight conditions (weightlessness, high charge, high radiation, high energy particles, and other space factors) and those on Earth, and the unique environment of space may cause DNA variations in seeds of $R$. pseudoacacia. Thus, we suspect that the higher genetic diversity and morphologic variation observed in the SM R. pseudoacacia were caused by short-term spaceflight of the original seeds or reflect their adaptive response to space environments after growth on Earth. Similar results were reported by Wu et al. (2011) using ISSR markers to study genetic diversity of Cistanche deserticola after spaceflight. Their results also showed that the genetic diversity of the spaceflight specimens was higher than that of the ordinary specimens. Nechitailo et al. (2005) conducted an amplification analysis on the genomic DNA of tomato seedlings grown from seeds carried in the Russian MIR space station using RAPD technology. The results showed that, compared with the controls, plants from seeds carried in the space station generated different band patterns of amplified fragments. The rates of DNA mutations in the 5 plants from seeds carried in the space station were 8.4, 3.2, 2.8, 6.0, and $9.2 \%$, and the rates of DNA mutation in controls were 0 and $0.4 \%$.

The degree of polymorphism exhibited by the SSR and SRAP banding patterns in our study was relatively high (approximately 85 and 90\%, respectively). Seedlings from 23 seed sources representing the natural range of black locust ( $R$. pseudoacacia L.) were electrophoretically analyzed at 40 structural loci representing 18 enzyme systems by Surles et al. (1989), and an average of $71 \%$ polymorphism was found. Sun et al. (2009) observed a $93.41 \%$ rate of polymorphism in 10 populations of $R$. pseudoacacia in China using 10 selected primers for ISSR. Both of these studies indicated that $R$. pseudoacacia maintains very high levels of genetic diversity. Thus, we attributed the high degree of polymorphism as measured by SSR and SRAP banding patterns in our study to the higher level of genetic diversity of R. pseudoacacia.

The results of the present study demonstrate that the higher level of genetic diversity and morphologic variation in the SM group compared to the OS group might be caused by short-term spaceflight of the original seeds or could reflect their adaptive response to space environments after growth on Earth. 


\section{CONCLUSION}

The present results showed molecular and morphological differences between the SM and OS groups. This suggests that the SSR and SRAP markers are effective for studying mutations and genetic diversity of $R$. pseudoacacia. These results indicate that genetic variation in $R$. pseudoacacia populations increases to some extent after spaceflight.

This is the first report to demonstrate the applicability of 2 molecular marker methods combined with morphological traits for evaluating the extent of mutation after spaceflight in forest trees. In addition, to the best of our knowledge, this is the first demonstration that spaceflight causes mutations in forest trees and increases genetic variation at the population level.

However, our study only identified differences between the SM and OS groups. For a better understanding of the mechanism of mutations (e.g., mutation rate and types) induced by spaceflight, further experiments will be necessary. Specifically, it will be important to select variants and clone and sequence the mutated fragments. This further study is currently in progress.

Our study investigated the molecular and morphologic effects of spaceflight on $R$. pseudoacacia seedlings obtained from seeds that endured a 15-day flight. Our results may provide valuable molecular evidence for the effects of the space environment on forest tree species and may contribute to future space breeding programs of forest trees.

\section{ACKNOWLEDGMENTS}

Research supported by the Special Fund Project for the Scientific Research of the Forest Public Welfare Industry (\#201104013), the National Science Foundation of China (\#31170629, \#30640036), and the Chinese Academy of Agricultural Sciences (\#2006HT100130). We also thank Dr. Gan Siming and Li Zhouqi for their kind help with revision of the manuscript and for valuable discussions. We also thank Professor Li Genqian for his enlightening discussions.

\section{REFERENCES}

Chen DP, Li L, Shen SH and Yang Q (2009). Optimization of SRAP-PCR system and M1 mutation molecular identification of M1 in Jatropha curcas L. Acta Agric. Nucl. Sin. 23: 209-213.

Gao WY, Fu RZ, Fan L, Zhao SP, et al. (2000). The effects of spaceflight on soluble protein, isoperoxidase, and genomic DNA in Ural Licorice (Glycyrrhiza uralensis Fisch). J. Plant Biol. 43: 94-98.

Gao W, Li K, Yan S, Gao X, et al. (2009). Effects of space flight on DNA mutation and secondary metabolites of licorice (Glycyrrhiza uralensis Fisch.). Sci. China C Life Sci. 52: 977-981.

He JJ, Liu FZ, Chen YH, Yang WC, et al. (2010). Effect of space flight mutation on Eggplant and analysis of genetic diversity by SSR molecular marker. J. Nucl. Agric. Sci. 24: 460-465.

Li G and Quiros CF (2001). Sequence-related amplified polymorphism (SRAP), a new marker system based on a simple PCR reaction: its application to mapping and gene tagging in Brassica. Theor. Appl. Genet. 103: 455-461.

Li Y, Liu M, Cheng Z and Sun Y (2007). Space environment induced mutations prefer to occur at polymorphic sites of rice genomes. Adv. Space Res. 40: 523-527.

Lian C and Hogetsu T (2002). Development of microsatellite markers in black locust (Robinia pseudoacacia) using a dualsuppression-PCR technique. Mol. Ecol. Notes 2: 211-213.

Lian C, Oishi R, Miyashita N and Hogetsu T (2004). High somatic instability of a microsatellite locus in a clonal tree, Robinia pseudoacacia. Theor. Appl. Genet. 108: 836-841.

Liu L, Van Zanten L, Shu QY and Maluszynski M (2004). Officially released mutant varieties in China. Mutat. Breed. Rev. 14: 1-64.

Liu M, Li JG, Wang YL, Zhang Z, et al. (1999). Preliminary study on peroxidase isoenzyme detection and RAPD molecular verification for sweet pepper 87-2 carried by a recoverable satellite. Acta Agric. Nucl. Sin. 13: 291-294. 
Lu JY, Zhang WL, Xue H, Pan Y, et al. (2010). Changes in AFLP and SSR DNA polymorphisms induced by short-term space flight of rice seeds. Biol. Plant. 54: 112-116.

Mashinsky AL and Nechitailo GS (2001). Results and prospects of studying the gravitationally sensitive systems of plants under conditions of space flight. Cosmic Res. 39: 317-327.

McCouch SR, Teytelman L, Xu Y, Lobos KB, et al. (2002). Development and mapping of 2240 new SSR markers for rice (Oryza sativa L.). DNA Res. 9: 199-207.

Mishima K, Hirao T, Urano S, Watanabe A, et al. (2009). Isolation and characterization of microsatellite markers from Robinia pseudoacacia L. Mol. Ecol. Resour. 9: 850-852.

Nechitailo GS, Lu JY, Xue H, Pan Y, et al. (2005). Influence of long term exposure to space flight on tomato seeds. $A d v$. Space Res. 36: 1329-1333.

Nei M (1973). Analysis of gene diversity in subdivided populations. Proc. Natl. Acad. Sci. U. S. A. 70: 3321-3323.

Normile D and Yimin D (2002). Space science. Science emerges from shadows of China's space program. Science 296: 1788-1791.

Powell W, Machray GC and Provan J (1996). Polymorphism revealed by simple sequence repeats. Trends Plant Sci. 1: 215-222.

Stringer JW and Carpenter SB (1986). Energy yield of black locust biomass fuel. Forest Sci. 32: 1049-1057.

Sun BJ, Li ZX, Luo SB, Li ZL, et al. (2010). Induced effects of space flight on Eggplant (Solanum melongena L.) and AFLP analysis on mutants. Plant Physiol. Comm. 46: 1205-1210.

Sun F, Yang MS, Zhang J and Gu JT (2009). ISSR analysis of genetic diversity of Robinia pseudoacacia populations. J. Plant Genet. Res. 10: 91-96.

Surles SE, Hamrick JL and Bongarten BC (1989). Allozyme variation in black locust (Robinia pseudoacacia). Can. J. Forest Res. 19: 471-479.

The People's Republic of China Ministry of Agriculture (2002). New Plant Varieties for Distinctness, Uniformity and Stability Testing Guidelines of China. China Agriculture Press, Beijing.

Wang WT, Chan CG, Ni DP and Wang ZF (2009). Space flight effects analysis of SP2 Salvia miltiorrhiza Bge using SRAP marker. Acta Agric. Nucl. Sin. 23: 758-761.

Wu Y, Yang DY, Tu PF, Tian YZ, et al. (2011). Genetic differentiation induced by spaceflight treatment of Cistanche deserticola and identification of inter-simple sequence repeat markers associated with its medicinal constituent contents. Adv. Space Res. 47: 591-599.

Xiao WM, Yang QY, Chen ZQ, Wang H, et al. (2009). Blast-resistance inheritance of space-induced rice lines and their genomic polymorphism by microsatellite markers. Agr. Sci. China 8: 387-393.

Xie LB, Guo YH, Meng FJ and Liu LX (2010). Molecular detection of genome DNA variation induced by space environment in Sweet Pepper (Capsicum annuum L.). Acta Agric. Nucl. Sin. 24: 254-258.

Yi JC, Zhuang CX, Yao J, Wang H, et al. (2002). DNA polymorphic analysis of rice mutation induced by space flight with molecular markers. Acta Biophys. Sin. 18: 478-483.

Yuan CQ, Li YF, Yang NN, Dai L, et al. (2011). Optimization of SRAP-PCR system and selection of primers for Robinia pseudoacacia L. Mol. Plant Breed. 9: 1182-1188.

Zhou GY, Hong YB, Lin KY, Li SX, et al. (2007). Study on breeding of space mutants in peanut and analysis of genetic diversity based on SSR marker. Chin. J. Oil. Crop Sci. 29: 238-241. 